KFKI-1983-28

$A, A$, GALEEV

$T, E$, CRAVENS

$T, I$, GOMBOS I
SOLAR WIND STAGNATION NEAR COMETS

Fungarian Academy of Sciences CENTRAL RESEARCH INSTITUTE FOR PHYSICS 
2011 


\title{
SOLAR WIND STAGNATION NEAR COMETS
}

\author{
A.A. GALEEV \\ Space Research Institute, USSR Academy of Sciences \\ 117810 Moscow, USSR \\ T.E. CRAVENS \\ Space Physics Research Laboratory, University of Michigan \\ Ann Arbor, MT 48109, USA \\ T. I. GOMBOSI \\ Central Research Institute for Physics \\ H-1525 Budapest 114, P.O.B. 49, Hungary
}

Submitted to Astrophys. Journal 


\section{ABSTRACT}

The nature of the solar wind flow near comets is examined analytically in this paper. In particular, typical values for the stagnation pressure and magnetic barrier strength are estimated, taking into account magnetic field line tension and charge exchange cooling of the mass loaded solar wind. A knowledge of the strength of the magnetic barrier is required in order to determine the location of the contact discontinuity which separates the contaminated solar wind plasma and the outflowing plasma of the cometary ionosphere.

\section{АННОТАЦИЯ}

Изучаются аналитические решения для описания течения солнечного ветра около комет. Даются оценки давления торможения и интенсивности магнитного барьера при типичных величинах параметров с учетом давления магнитных силовых линий и реакций обмена зарядов солнечного ветра путем добавления масс. Интенсивность магнитного барьера может служить для определения места контактного разрыва, разделяющего плазму солнечного ветра от распространяющейся ионосФеры комет.

\section{KIVONAT}

A cikkben a napszél üstökösök körüli áramlását leiró analitikus megoldásokat keresünk. Tipikus paraméterértékek mellett becsléseket adunk a stagnációs nyomásra és a mágneses akadály erốsségére a mágneses erôvonalak nyomásának és a tömeghozzáadással szennyezett napszél töltéscserés reakcióinak figyelembevételével. A mágneses akadály erôsségének ismerete elengedhetetlen a napszélplazmát és az expandáló üstökös ionoszférát elválasztó kontakt diszkontinuitás helyẻnek meghatározása céljából. 


\section{INTRODUCTION}

The magnetic barrier serves as a buffer between the contaminated solar wind and the outflowing cometary plasma. Its strength $1 \mathrm{~s}$ defined by the solar wind stagnation pressure and 1ts position depends on the stagnation pressure of the outflowing cometary plasma and the drag imposed by the outflowing neutral gas on the cometary plasma frozen into the solar wind magnetic field. Gas dynamical calculations in the case of the ratio of specific heats $\gamma=2$ give a value of the solar wind stagnation pressure behind the shock (with a Mach number, $M=2$ ) equal to 0.84 of the dynamic pressure of the unperturbed solar wind (Landau and Lifshitz, 1959, p. 458). Introduction of a source term describing the solar wind mass loading by cometary ions reduces the stagnation pressure to about 0.6 of the dynamic pressure of the unperturbed solar wind (Schmidt and Wegmann, 1982). This value is further modified by the magnetic pressure increase associated with magnetic tension forces imposed on the stagnating solar wind plasma. We will show in this paper that the cooling of the contaminated solar wind plasma by the charge exchange with cometary neutrals strongly influences the solar wind flow in the stagnation region and thus affects the formation of the magnetic barrier. The review by Ip and Axford (1982) discusses many of these issues. In order to consider this effect we use a simple kinetic description of the solar wind mass loading by cometary ions.

Since the position and the structure of the magnetic barrier is strongly dependent on the characteristics of the outflowing cometary plasma we also discuss the nature of the pressure balance at the contact discontinuity.

\section{KINETICS OF THE COMETARY IONS IN THE SOLAR WIND}

As we have mentioned above, the proper consideration of the charge exchange processes near comets a kinetics treatment of the problem. A self-consistent description of the unshocked solar wind flow with the cometary ions continuously implanted into it is given by the following set of equations (see Wallis and Ong, 1973): 


$$
\begin{gathered}
\frac{d}{d x}\left[\rho_{i} u f(u, \mu)\right]=\frac{Q_{n} m_{1}}{4 \pi v_{g} \tau r^{2}} \cdot \delta\left(\mu-\frac{m_{i} u^{2}}{2 B}\right) \\
\frac{d(\rho u)}{d x}=\frac{Q_{n} m_{i}}{4 \pi v_{g} \tau r^{2}}, \\
\frac{d}{d x}\left(\rho u^{2}+p_{\perp}+\frac{B^{2}}{8 \pi}\right)=0
\end{gathered}
$$

where the $x$-axis is directed from the sun to the cometary nucleus, $r$ is the distance from the nucleus, $\rho_{i} i s$ the mass density of cometary ions, $\rho i s$ the mass density of contaminated solar wind, $u$ is the hydrodynamical velocity, $B$ is the strength of the magnetic field (that is assumed to be perpendicular to the flow), $p_{\perp}$ is the gas kinetical pressure of the plasma, $f(u, \mu)$ is the velocity distribution of cometary ions, and $\mu=m_{i} v_{\perp}^{2} / 2 B$ is the magnetic moment of cometary ions. The source term on the right hand side of the equation (1) is obtained by assuming a given production rate $Q_{n}$ of cometary gas consisting of only a single species with mass $m_{i}$, a constant gas outflow velocity, $V_{g}$, and a characteristic time $\tau$ for photoionization.

The solution of equations (1) and (2) has the form

$$
\rho_{i} u f(u, \mu)=\int_{u_{\infty}}^{u} \frac{d\left(\rho^{\prime} u^{\prime}\right)}{d u^{\prime}} \cdot \delta\left(\mu-\frac{m_{i} u^{\prime 2}}{2 B}\right) d u^{\prime},
$$

where the subscript $\infty$ refers to unperturbed solar wind parameters. For typical hypersonic $\left(M_{A \infty}=4 \pi \rho_{\infty} u_{\infty}^{2} / B_{\infty}^{2} \gg 1\right)$ and low $\beta\left(\beta=8 \pi p_{\perp_{\infty}} / B_{\infty}^{2}>1\right)$ solar wind flow, we can neglect the gas kinetic pressure of solar wind protons and electrons as well as the magnetic pressure. Thus the plasma pressure is equal to the pressure of cometary ions in the solar wind:

$$
p_{\perp} \simeq p_{\perp_{i}}=\int_{m_{i} u^{2} / 2 B}^{m_{i} u_{\infty}^{2} / 2 B_{\infty}} \rho_{i} f(u, \mu)\left(\frac{\mu B}{m_{i}}\right) d \mu
$$

Substituting this expression into the equation (3), we find the following relation between ou and $u$ that describes the gas dynamical flow with ratio of specific heats $\gamma=2$ (see for example Landau and Lifshitz, 1959):

$$
\rho u=\rho_{\infty} u_{\infty}\left(\frac{4 u_{\infty}}{3 u}-\frac{u_{\infty}^{2}}{3 u^{2}}\right) \text {. }
$$

This relation combined with equations (2) and (3) describes the contaminated solar wind flow in the form (Biermann et al., 1.967) 


$$
\begin{aligned}
& \hat{\rho} \hat{u}=1+\frac{Q_{n} m_{1}}{4 \pi v_{g}^{\tau \rho_{\infty} u_{\infty}}} \cdot \frac{1}{r} \\
& \hat{a}=\frac{2}{3 \hat{\rho} \hat{\hat{\alpha}}}\left(1 \pm \sqrt{1-\frac{3}{4} \hat{\mathrm{o}} \hat{\mathrm{a}}}\right) \\
& \hat{\rho}=2 \hat{\rho} \hat{Q}\left(1 \mp \sqrt{1-\frac{3}{4} \hat{\rho} \hat{Q}}\right) \\
& \hat{\mathrm{p}}=\frac{1}{3}\left(1 \mp 2 \sqrt{1-\frac{3}{4} \hat{\mathrm{\rho}} \hat{\mathrm{u}}}\right)
\end{aligned}
$$

where $\hat{\rho}, \hat{a}, \hat{\mathrm{p}}$ are the solar wind parameters normalized to their unperturbed values $\rho_{\infty}, u_{\infty}, \rho_{\infty} u_{\infty}^{2}$, respectively.

It is well known that continuous solar wind flow is possible only until the point at which the mean molecular weight of solar wind particles reaches the critical value $\hat{\rho} \hat{Q}=4 / 3$ (Biermann et al, 1967). Numerical simulations (Schmidt and Wegmann, 1982) show, in fact, that for a gas production rate of the order of that for comet Halley $\left(Q_{n}=2.5 \times 10^{29} \mathrm{H}_{2} \mathrm{O}\right.$ molecules per second) a shock wave with Mach number $M=2$ forms in the solar wind at a distance from the nucleus of:

$$
R_{S}=\frac{Q_{n} m_{i}}{4 \pi V v^{\tau \rho_{\infty} u_{\infty}\left[(\rho Q)_{C}-1\right]}},
$$

where $(\hat{p} \hat{a})_{C}=1.185$.

The velocity distribution of cometary ions in the unshocked solar wind is given by equation ( 4 ) with $d(p u) / d u$ defined by the equation ( 6 ) and $B=$ $=\mathrm{B}_{\infty} \mathrm{u}_{\infty} / \mathrm{u}$ for the magnetic field frozen into the plasma flow (Wallis and ong, 1975):

$$
\rho_{i} u f(u, \mu)=\frac{4\left[\left(\frac{\mu}{\mu_{\infty}}\right)^{1 / 3}-0.5\right]}{9\left(\frac{\mu}{\mu_{\infty}}\right)^{5 / 3} \cdot \mu_{\infty}} \rho_{\infty} u_{\infty} \Theta\left(\mu_{\infty}-\mu\right) \Theta\left(\mu-\mu_{\infty} \cdot \frac{u^{3}}{u_{\infty}^{3}}\right)
$$

where $\Theta(x)=1$ for $x \geq 0$ and $\Theta(x)=0$ for $x<0$; $\mu_{\infty}=m_{i} u_{\infty}^{2} / 2 B_{\infty}$.

This distribution is highly non-monotonic in energy and highly anisotropic $\left(p_{\perp} \gg p_{n}\right)$; and thus it is expected to be unstable with respect to loss-cone modes (Post and Rosenbluth, 1965) and to "mirror" type perturbations (Vedenov and Sagdeev, 1958). The analysis of Galeev (1982) shows that the growth of the loss-cone modes is limited by non-linear effects and the "mirror" type perturbations are convected by the solar wind flow so rapidly that they have no time to grow. Therefore, the adiabatic approximation that was used to find the cometary ion distribution in the unshocked solar wind, can be considered to be a good approximation.

In contrast to the flow ahead of shock, for the solar wind flow behind the shock we expect rapid isotropization of the velocity distribution due to particle scattèring by magnetic field fluctuations resulting from the mirror 
instability. Taking this into account, we will use the following set of equations to describe the shocked solar wind flow along the stagnation 1ine (for details see Galeev, 1982):

$$
\begin{gathered}
\frac{1}{A} \cdot \frac{d}{d x}\left[\rho_{i} \operatorname{uAf}(u, \varepsilon)\right]=\frac{Q_{n} m_{i}}{4 \pi v_{g} \tau r^{2}} \delta\left(\varepsilon-\frac{m_{i} u^{2}}{2}\right)-\sigma_{c t}\left(\frac{2 \varepsilon}{m_{i}}\right)^{1 / 2} \rho_{i} f(u, \varepsilon) \frac{Q_{n}}{4 \pi v_{g} r^{2}}, \\
\frac{1}{A} \cdot \frac{d}{d x}(\rho u A)=\frac{Q_{n} m_{i}}{4 \pi v_{g} \tau r^{2}}, \\
\frac{1}{A} \cdot \frac{d}{d x}\left(\rho u^{2} A\right)+\frac{d p_{\perp}}{d x}=-\frac{d}{d x} \cdot \frac{B^{2}}{8 \pi}-\frac{B^{2}}{4 \pi r_{c}},
\end{gathered}
$$

where

$$
p_{\perp}=\frac{2}{3} \int_{0}^{\infty} \frac{\varepsilon}{m_{1}} \rho_{i} f(u, \varepsilon) d \varepsilon
$$

is the pressure of cometary ions, $A(x)$ is the flow tube area, $\varepsilon$ is the energy of a cometary ion, $\sigma_{c t}$ is the charge exchange cross-section. The last term in Eq. (11) describes the charge exchange loss of the energetic cometary 1ons $\left(\varepsilon>m_{i} u^{2} / 2\right)$ that were accreted earlier (upstream) in the flow. The new cometary ions resulting from this charge exchange are less energetic and thus do not contribute much to the thermal energy of cometary ions (1.e. the gas kinetic pressure of plasma).

We assume here that the flow of the shocked subsonic solar wind is near1y incompressible for protons and electrons so that $u A=$ const since this is in agreement with numerical simulations (Brosowski and Wegmann, 1972). In this case the solution to equations (11) and (12) can be written in the form:

$$
\begin{gathered}
\rho_{i} f(u, \varepsilon)=\exp \left[-\sigma_{c t} \tau\left(\frac{2 \varepsilon}{\left.m_{i}^{3}\right)^{1 / 2}}\left(\rho-\rho_{2}\right)\right]\left\{\rho_{i_{2}} f\left(u_{2}, \varepsilon\right)+\right.\right. \\
\left.+\int_{\rho_{2}}^{\rho} d \rho^{\prime} \delta\left(\varepsilon-\frac{m_{i} u^{\prime 2}}{2}\right) \exp \left[\sigma_{c t} \tau\left(\frac{2 \varepsilon}{m_{i}^{3}}\right)^{1 / 2}\left(\rho^{\prime}-\rho_{2}\right)\right]\right\},
\end{gathered}
$$

where $\rho_{i_{2}} f\left(u_{2}, \varepsilon\right)$ is the energy distribution of cometary ions just behind the shock. In order to find it we must specify the structure of the cometary bow shock.

In agreement with the numerical simulations of Schmidt and Wegmann (1982), we assume here that the Mach number of the shock is $M=2$. Since the upstream plasma has high $\beta=8 \pi p_{\perp_{i}} / B_{1}^{2} \gg 1$, the dissipation within the shock front can be provided only by anomalous viscosity resulting from the instability of counterstreaming solar wind ions within the shock front (Sagdeev, 
1964). This kind of dissipation takes place within characteristic distances of the order of proton Larmor radius. But the isotropization of the plasma ions (protons and cometary ions) should take place in a region with a spatial scale of the order of the cometary ion larmor radius. Thus the shock structure consists of a viscous subshock and a much more extended region of isotropization, where some additional dissipation of energy of the plasma flow still proceeds.

Let us first consider the deformation of the velocity distribution of cometary ions at the viscous subshock. Since the width of the subscock is much smaller than the Larmor radius of a cometary ion, we approximate the subshock structure by the jump of solar wind parameters (see Fig. 1).

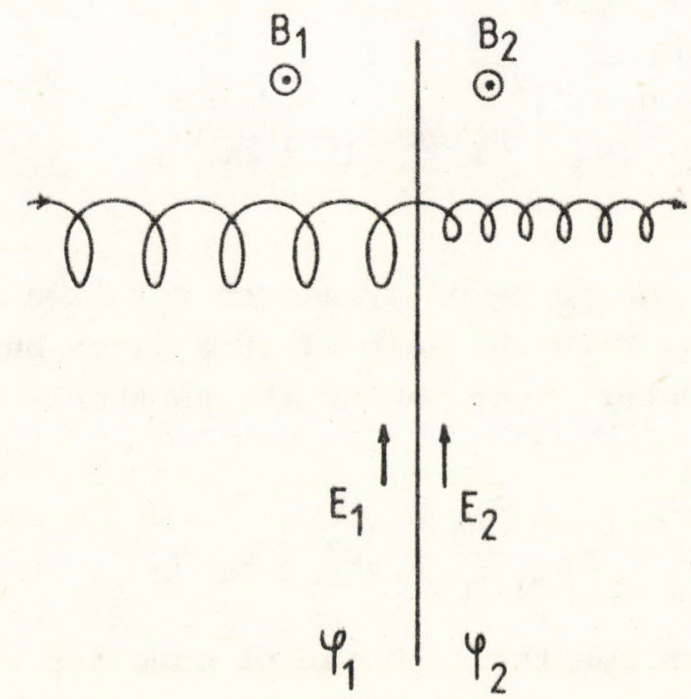

Fig. 1 The schematic representation of cometary ion motion across the viscous subshock

These parameters on both sides of the shock are given by equation ( 8 ) with $(\hat{\mathrm{o}} \mathrm{Q})_{\mathrm{C}}=32 / 27$ :

$$
\begin{array}{lll}
\hat{a}_{1}=0.75 & \hat{\rho}_{1}=1.58 & \hat{\mathrm{p}}_{1}=1 / 9 \\
\hat{a}_{2}^{\prime}=0.375 & \hat{\mathrm{o}}_{2}^{\prime}=3.16 & \hat{\mathrm{p}}_{2}^{\prime}=5 / 9
\end{array}
$$

The cometary ions drift with the velocity $u=c \cdot E / B$ and simultaneously rotate around the magnetic field line with the velocity $\sqrt{2 \mu \mathrm{B} / \mathrm{m}_{1}}$. The tangential component of the electric field is constant across the shock $\left(E_{1}=E_{2}\right)$ so that $u_{1} B_{1}=u_{2} B_{2}$. There is an electrostatic potential jump across the shock of $\varphi_{2}-\varphi_{1} \equiv \Delta \varphi \sim m_{p}\left(u_{1}^{2}-u_{2}^{2}\right) / e$ that decelerates the protons. Its effect on the velocity of cometary ions is negligible $\left(e \Delta s<m_{i}\left(u_{1}^{2}-u_{2}^{2}\right)\right)$. Therefore, the velocity of cometary ions is continuous across the shock, i.e. 


$$
\begin{aligned}
& u_{1}+\sqrt{\frac{2 \mu_{1} B_{1}}{m_{1}}} \cos \phi_{1}=u_{2}^{\prime}+\sqrt{\frac{2 \mu_{2}^{\prime} B_{2}^{\prime}}{m_{1}}} \cos \phi \\
& \sqrt{\frac{2 \mu_{1} B_{1}}{m_{i}}} \sin \phi_{1}=\sqrt{\frac{2 \mu_{2}^{\prime} B_{2}^{\prime}}{m_{i}}} \sin \phi_{2}^{\prime},
\end{aligned}
$$

where $\phi$ is the phase angle of the Larmor rotation. Taking into account the (1) continuity equation for ions we immediately find:

$$
\begin{aligned}
\rho_{2}^{\prime} u_{2}^{\prime} f_{2}\left(u_{2}^{\prime}, \mu\right) & =\rho_{1} u_{1} \int_{\mu_{\infty} u_{1}^{3} / u_{\infty}^{3}}^{\mu_{\infty}} f\left(u_{1}, \mu_{1}\right) \int_{0}^{2 \pi} \delta\left(\mu_{1} \cdot \frac{B_{1}}{B_{2}^{\prime}}+\frac{m_{1}}{2 B_{2}^{\prime}}\left[u_{1}-u_{2}\right]^{2}+\right. \\
& +2 \sqrt{\left.\frac{m\left[u_{1}-u_{2}^{\prime}\right]^{2}}{2 B_{2}^{\prime}} \mu_{1} \cdot \cos \phi_{1}-\mu\right) \frac{d \phi_{1}}{2 \pi} d \mu_{1}} .
\end{aligned}
$$

Here we integrated over the phase of cyclotron rotation which are uniformly distributed from 0 to $2 \pi$. With the help of this distribution we can easily find the pressure of cometary ions behind the subshock:

$$
p_{i_{2}}^{\prime}=p_{\perp_{i}} \frac{\rho_{i_{2}}^{\prime}}{\rho_{1}}+\frac{1}{2} \rho_{i, 2}^{\prime}\left(u_{1}-u_{2}\right)^{2}
$$

The first term here describes the increase of cometary ion pressure due to the density increase. The second one describes non-adiabatic effects and it is smaller by an ordex of magnitude. Neglecting these effects we can rewrite expression (17) in a simpler form

$$
\rho_{2}^{\prime} u_{2}^{\prime} f_{2}\left(u_{2}^{\prime}, \mu\right)=\rho_{1} u_{1} f\left(u_{1}, \mu_{\frac{1}{B_{1}}}^{\prime}\right) .
$$

After the plasma isotropization behind the viscous subshock the flow velocity drops and the plasma pressure increases.

The plasma parameters behind the cometary bow shock now can be computed from the equations of plasma flow with $\gamma=5 / 3$ (Biermann et al, 1967) (compare with Eq. (7))

$$
\begin{gathered}
\hat{a}_{2}=\frac{\gamma}{\gamma+1} \frac{1}{\hat{\rho} \hat{a}}\left[1-\sqrt{\left.1-\frac{\gamma^{2}-1}{\gamma^{2}} \hat{\rho} \hat{u}\right]}\right. \\
\hat{\rho}_{2}=\hat{\rho} \hat{u} / \hat{a}_{2}, \\
\hat{p}_{2}=1-\hat{\rho} \hat{u} \cdot u_{2}
\end{gathered}
$$

For ồ $=1.182$ corresponding to $\mathrm{M}=2$ we find 


$$
\begin{gathered}
-7- \\
\hat{a}_{2}=0.268 \quad \hat{\mathrm{o}}_{2}=4.42 \quad \hat{\mathrm{p}}_{2}=0.682
\end{gathered}
$$

The energy distribution of cometary ions changes adiabatically in the isotropization process, so that (see Eq. (19)):

$$
\rho_{2} u_{2} f_{2}\left(u_{2}, \varepsilon\right)=\rho_{1} u_{1} f\left(u_{1},\left[\frac{\varepsilon}{\hat{B}_{1}}\right]\left[\frac{\rho_{2}^{\prime}}{\rho_{2}}\right]^{2 / 3}\right) / \hat{B}_{1}\left(\rho_{2} / \rho_{2}^{\prime}\right)^{2 / 3} .
$$

III. THE STAGNATION OF SOLAR WIND FLOW

Using the distribution function of cometary ions we can calculate their pressure by using equation (1.3):

$$
p_{\perp_{i}}=\frac{2}{3} \int \frac{\varepsilon}{m_{i}} \rho_{i} f(u, \varepsilon) d \varepsilon
$$

As can be seen from the comparison of the two terms in expression (14) for $f(u, \varepsilon)$, the largest contribution to the pressure of cometary ions comes from the ions born in the unshocked solar wind. These particles contain $2 / 5$ of the total plasma pressure behind the shock. Their energy is so large $\left(\varepsilon \geqslant m_{i} u_{\infty}^{2} / 2\right)$ that even infrequent charge exchange collisions can cool them effectively. We consider the effect of cooling using an approximation of slow charge exchange process where we can expand the corresponding exponent in the first term of expression (14). At the same time we neglect the cooling of ions born in the shocked solar wind (second term in the expression (14)) since their energy is much smaller and therefore the charge exchange processes for them are much slower. As a result we obtain the following expression for the cometary ion pressure force:

$$
\frac{d p_{\perp_{i}}}{d x}=\frac{1}{3} u^{2} \cdot \frac{d p}{d x}-\frac{4}{3} a u_{2}^{2} \cdot \frac{d p}{d x}
$$

where

$$
\alpha=\frac{1}{9}\left(\frac{B_{1}}{B_{\infty}}\right)^{3 / 2}\left(\frac{u_{\infty}}{u_{2}}\right)^{3} \frac{\rho_{2}}{\rho_{2}^{\prime}} \cdot \frac{m_{p}}{m_{i}} \int_{\left(u_{1} / u_{\infty}\right)^{3}}^{1} d \tilde{\varepsilon}\left(\tilde{\varepsilon}^{1 / 6}-0.5 \tilde{\varepsilon}^{-1 / 6}\right) .
$$

The first term here describes the build up of the cometary pressure due to the creation of new ions in the shocked solar wind by photoionization of the cometary gas. The second term represents the cooling effect.

If we now take into account the fact that the proton pressure stays constant in the flow with $U A=$ const (Schmidt and Wegmann, 1982) we can write the equation of plasma motion (13) in the form: 


$$
u \frac{d}{d x} \rho u+\frac{1}{3} u^{2} \cdot \frac{d \rho}{d x}=\frac{4}{3} a u_{2}^{2} \cdot \frac{d \rho}{d x}-\frac{d}{d x} \cdot \frac{B^{2}}{8 \pi}+\frac{B^{2}}{4 \pi r}
$$

\section{a./ Gas dynamical flow}

In the limit of no cooling $(\alpha+0)$ and low magnetic field $(B+0)$ the solution to Eq. (26) is (Wallis, 1973):

$$
\rho=\rho_{2}\left(\frac{u_{2}}{u}\right)^{3 / 4} .
$$

Combined with equation (12) it gives the profile of plasma flow velocity

$$
u=u_{2}\left(1-\frac{R_{L}}{r}\left[1-\frac{r}{R_{S}}\right]\right) \quad,
$$

where $R_{L}=Q_{n} m_{i} / 12 \pi V_{g} \tau \rho_{2} u_{2}$ is the characteristic spatial scale of the solar wind mass loading region, and $r$ is the distance from the cometary nucleus along the stagnation line. At the stagnation point, $r=R_{L}$, the plasma pressure reaches its stagnation value for gas dynamical flow with $\gamma=5 / 3$ (see equations (21) and (24)):

$$
p_{\text {stag }}=p_{2}-\rho_{2} \frac{u_{2}^{2}}{5}=0.745 \rho_{\infty} u_{\infty}^{2} \text {. }
$$

\section{b./ Magnetic field effects}

However, in the presence of the magnetic field or plasma cooling, the flow of the contaminated solar wind does not stop at $r=R_{L}$. To estimate the relative importance of these two effects, we use the relation between the magnetic field and the flow velocity that holds for the conservative component of the flow (in our case these are protons) in the case of the axisymmetric flow along the stagnation line (Lees, 1964):

$$
\frac{\mathrm{B}^{2} \mathrm{u}}{\mathrm{n}_{\mathrm{p}}}=\mathrm{const} \text {, }
$$

where $n_{p}$ is the proton density that is constant in the shocked solar wind flow ( $n_{p} \simeq$ const). With the help of this relation we can find that the relative importance of the magnetic pressure:

$$
\frac{d}{d x} \cdot \frac{B^{2}}{4 \pi r_{c}}=4 \frac{B_{\infty}^{2}}{4 \pi r_{c}}\left(\frac{u_{\infty}}{u_{2}}\right) \frac{u_{2}}{u} \cdot \frac{1}{R_{L}}
$$

and the cooling term:

$$
\frac{4}{3} a u_{2}^{2} \cdot \frac{d \rho}{d x}=4 a \rho_{2} u_{2}^{2}\left(\frac{u_{2}}{u}\right) \frac{1}{R_{L}}
$$

depends only on solar wind parameters. The magnetic tension force dominates for 


$$
M_{A}=\frac{4 \pi \rho_{\infty} u_{\infty}^{2}}{B_{\infty}^{2}}<\left(\frac{u_{\infty}}{u_{2}}\right)^{3} \frac{1}{\alpha}
$$

For a typical solar wind density, $\mathrm{n}_{\infty} \simeq 6 \mathrm{~cm}^{-3}$, and velocity $\mathrm{u}_{\infty}=400 \mathrm{~km} / \mathrm{sec}$, charge exchange cross section, $\sigma_{c t}=2 \times 10^{-15} \mathrm{~cm}^{2}$, and ionization time $\tau=$ $=10^{6}$ sec, this inequality is satisfied for interplanetary magnetic field stronger than $\sim 5 \mathrm{r}$. In this case, the magnetic pressure slows down the flow near $r=R_{L}$ further on and this. leads to magnetic pressure build up at the expense of plasma pressure. Meanwhile the curvature of the magnetic field lines increases and finally magnetic tension force takes over the magnetic pressure force, thereby reaccelerating plasma flow under the action of tension force imposed by the rapidly flowing solar wind plasma outside the stagnation region (Schmidt and Wegmann, 1982).

The flow along the stagnation line continues with a velocity proportional to $r^{0.5}$. This scaling law can be easily found from equation (26) with only the tension force left in on the right hand side of it. Then the magnetic field pressure continues to build up very slowly as,

$$
\frac{B^{2}}{8 \pi}=p_{s t a g}\left(\frac{r}{R_{L}}\right)^{1 / 2}
$$

This process ends at the distance of strong neutral gas - solar wind coupling due either to the charge exchange or simpoe collisions:

$$
R_{C}=\frac{Q_{n} \sigma_{c t}}{4 \pi V_{g}}
$$

So the total increase of the magnetic pressure can be about a factor of 3 :

$$
\frac{\mathrm{B}_{\max }^{2}}{8 \pi}=p_{\text {stag }}\left(\frac{3 \sigma_{c t} \rho_{2}}{m_{i} u_{2}^{\tau}}\right)^{-1 / 2} \approx 2.42 \rho_{\infty} u_{\infty}^{2} ; \quad\left(B_{\infty}>5 \gamma\right),
$$

where the numerical estimate is again made for a shock strength $M=2$ and the solar wind parameters specified above.

\section{c./ Plasma cooling effects}

In the case of a weak interplanetary field $\left(B_{\infty}<5 \gamma\right.$ ) we can neglect the magnetic forces in equation (26) for plasma notion. Then it is easily integrated with the result:

$$
\rho \cong \rho_{2}\left[\left(\frac{u}{u_{2}}\right)^{2}-\alpha\right]^{-3 / 8}
$$

The solution of the mass loading equation (12) now has a form 


$$
\frac{1}{4} \int_{u / u_{2}}^{1} \frac{d y}{\left[y^{2}-\alpha\right]^{3 / 8}}+\frac{\alpha}{4} \int_{u / u_{2}}^{1} \frac{d y}{\left[y^{2}-\alpha\right]^{11 / 8}}=\frac{R_{L}}{r}\left(1-\frac{r}{R_{s}}\right)
$$

It describes the initial slowing down of the contaminated solar wind flow due to the solar wind mass loading (see equations (27) and (28)) as well as the reacceleration of the flow due to the plasma cooling. The latter effect maintains the flow velocity at the level $u \simeq u_{2} \sqrt{\alpha}$ until the cometary ions will be cooled. Using the asymptotic solution of equations (35) and (36) in the form

$$
\frac{\rho}{\rho_{2}} \simeq \frac{1}{\left|\left(\frac{u}{u_{2}}\right)^{2}-\alpha\right|^{3 / 8}}=\frac{3}{\alpha^{1 / 2}}\left(\frac{R_{L}}{r}-1\right) .
$$

We find from equation (14) and (22) that the pressure of the cometary ions starts to decrease exponentially when

$$
\sigma_{\operatorname{ct}} \tau u_{\infty}\left(\frac{B_{1}}{B_{\infty}}\right)^{1 / 2}\left(\frac{\rho_{2}}{\rho_{2}^{1}}\right)^{\rho-\rho_{2}} \frac{m_{1}}{m_{1}}>1
$$

i.e.

$$
r<0.625 R_{L} \quad
$$

Then the flow is decelerated again by the magnetic pressure force. But the magnetic pressure now can grow only at the expense of the undeteriorated proton pressure which is twice lower than the stagnation pressure (29). As the consequence the pressure of the magnetic field in the real stagnation region at $r \simeq R_{C}$ will be also twice as low,

$$
\frac{\mathrm{B}_{\max }^{2}}{8 \pi} \simeq 1.2 \rho_{\infty} \mathrm{u}_{\infty}^{2} \quad\left(\mathrm{~B}_{\infty}<5 \gamma\right) .
$$

\section{THE CONTACT DISCONTINUITY}

The cometary ionospheric plasma in the inner coma expands radially outward from the nucleus at the neutral gas velocity due to ion-neutral collisions (see the review by Mendis and Houpis, 1982, for a general discussion of cometary ionospheres). The ionospheric plasma density can be calculated by solving the continuity equation including a source of ions such as photoionization and loss of ions by dissociative recombination (Gombosi et al., 1983, Mendis and Houpis, 1982). The contact discontinuity surface separates the contaminated shocked solar wind plasma from the ionospheric plasma and will form 
where the magnetic barrier pressure balances the ionospheric thermal pressure just inside the discontinuity.

The outflowing cometary plasma flow is expected to undergo a shock (the inner shock) so that the magnetic pressure of the barrier is balanced on the inside by the stagnated and shocked thermal ionospheric plasma (Mendis and Houpis, 1982). This stagnation pressure can be enhanced by ion-neutral drag due to the neutrals flowing past the stagnated ions. For radial distances of about $1000 \mathrm{~km}$ for comets with gas production rates like comet Halley's the enhancement factor should be about a factor of 2. The magnetic pressure associated with the magnetic barrier depends on the stagnation pressure of the shocked solar wind as discussed earlier in this paper. The stagnation pressure and barrier strength where shown to be enhanced by magnetic field line tension and weakened by cooling due to charge exchange. Inside the magnetic barrier, the magnetic field line tension must be balanced by the ion-neutral drag exerted by the outflowing neutrals on the cometary ions created within the barrier by photoionization or other ionization processes (Ip and Axford, 1982).

The pressure balance at the contact discontinuity can be represented by:

$$
F_{S} \rho_{\infty}\left(\vec{V}_{S W} \vec{n}\right)^{2}=F_{C} \rho_{C}\left(\vec{V}_{g} \vec{n}^{2} \quad,\right.
$$

where $\rho_{\infty}$ is the undisturbed solar wind mass density, $\vec{V}_{5 w}$ is the undisturbed solar wind bulk velocity vector, $\overrightarrow{\mathrm{V}}_{\mathrm{g}}$ is the cometary gas outflow velocity vector, $\rho_{C}$ is the mass density of the ionospheric plasma, and $\vec{n}$ is the unit normal vector of the contact surface.

$\mathrm{F}_{\mathrm{S}}$ is a correction factor which is usually about unity ( .84 was quoted earlier). That is, the stagnation pressure (and barrier strength) is almost equal to the dynamic pressure of the unperturbed solar wind. However, it was demonstrated earlier in this paper and by numerical simulations (Schmidt and Wegmann, 1982) that magnetic field tension can increase $\mathrm{F}_{\mathrm{S}}$ to as much as 2 or 3, for strong interplanetary fields. But for weak interplanetary fields, it was shown in this paper that cooling of the solar wind by charge exchange interactions can lead to a reduction of the stagnation pressure by about a factor of 2 (i.e., $\mathrm{F}_{\mathrm{S}} \simeq 0.5$ ). Similarly, $\mathrm{F}_{\mathrm{C}}$ relates the stagnation pressure of the ionospheric ions to the dynamic pressure of the outflowing plasma inside the inner shock. $\mathrm{F}_{\mathrm{C}}$ is probably about 2 due to ion-neutral drag. $\mathrm{F}_{\mathrm{S}} / \mathrm{F}_{\mathrm{C}}$ could unceivably range from 0.25 to about 2 or 3.

The location of the contact discontinuity can be obtained from equation (40) if the solar wind parameters and ionospheric plasma density are known. The latter can be found in Gombosi et al. (1983). Assuming typical solar wind conditions the values calculated by Gombosi et al. (1983) for the location of the contact discontinuity can be adjusted to take into account the values of $\mathrm{F}_{\mathrm{S}}$ and $\mathrm{F}_{\mathrm{C}}$ estimated in this paper. For comets with gas production rates like comet Halley and for lAU the location of the contact discontinuity will be between $\sim 75 \mathrm{~km}$ for high interplanetary magnetic field values to $\sim 600 \mathrm{~km}$ for low values. 


\section{CONCLUSIONS}

Using a simple axisymmetrical gas-dynamical model for the solar wind plasma flow in the cometary atmosphere along the stagnation line (Wallis, 1973) and the kinetic equation for cometary ions in the adiabatic approximation (see also Wallis and Ong, 1975) we were able to describe the following effects:

1./ The magnetic field build up in a mass loading region situated at the distance $R_{L}$ that is of the order of $0.1 R_{S}\left(R_{S}\right.$ is the cometary bow shock stand off distance).

2./ The enhancement of the pressure of the magnetic barrier by the tension imposed by the solar wind flow far from the stagnation line. Both these effects are clearly seen in numerical simulations (Schmidt and Wegmann, 1982).

3./ The reduction of the pressure of the magnetic barrier by a factor of 2 in the case of weak interplanetary magnetic field $\left(B_{\infty}<5 \gamma\right.$ ) due to the cometary ions cooling by the charge exchange process.

4./ The position of the contact discontinuity is determined by the pressure balance between the magnetic barrier pressure and the pressure of the stagnated outflowing cometary ions and is therefore sensitive to factors which affect the barrier strength such as magnetic tension and plasma cooling due to charge exchange.

VI. ACKNOWLEDGEMENTS

This work was supported jointly by the Hungarian Academy of Sciences and the National Science Foundation of the United States. Additional support at the Central Research Institute for Physics of the Hungarian Academy of Sciences was provided in the framework of the International Theoretical Workshop.

\section{REFERENCES}

Biermann, L., Brosowski, B. and Schmidt, H.U. (1967): The interaction of the solar wind with a comet, Solar Phys., $1,254-283$

Brosowski, B. and Wegmann, R. (1972): Numerische Behandlung eines Kometenmodells, Max-Planck Inst. für Physik und Astrophysik, Report, MPI/PAE-A Stro 46

Galeev, A.A. (1982): Collective plasma effects in the solar wind interaction with comets, paper presented at Int. Conf. on Cometary Expl., Bp., Hungary

Gombosi, T.I., Horányi, M., Kecskeméty, K., Cravens, T.E., Nagy, A.F. (1983): Charge exchange in solar wind cometary interactions, Astrophys. J.

Ip, W.-H. and Axford, W.I. (1982): Theories of physical processes in the cometary comae and ion tails, in: Comets (ed. Wilkening, L.L.), Univ. Arizona Press, pp. 588-634 
Landau, L.D. and Lifshitz, E.M. (1959): Fluid dynamics (Oxford, Pergamon Press)

Landau, L.D. and Lifshitz, E.M. (1960): Electrodynamics of continuous media (Oxford, Pergamon Press)

Lees, L. (1964): Interaction between the solar wind plasma and the geomagnetic activity, AIAA Journal, $\underline{2}$, 1576-1582

Mendis, D.A. and Houpis, H.L.F. (1982): The cometary atmosphere and its interaction with the solar wind, Rev. Geophys. Space Phys.

Rosenbluth, M.N. and Post, R.F. (1965): High frequency electrostatic plasma instability inherent to "loss-cone" particle distributions, Phys. Fluids, 8,547

Sagdeev, R.Z. (1964): Collisionless shocks in questions of plasma theory (ed. Leontovich, M.A.), Atomizdat, Moscow (in Russian)

Schmidt, H.U. and Wegmann, R. (1982): Plasma flow and magnetic fields in comets, in: Comets (ed. Wilkening, L.L.), Univ. Arizona Press, pp. 538-560

Vedenov, A.A. and Sagdeev, R.Z. (1958): Instability of a plasma with an anisotropic ion velocity distribution, in: Plasma Physics and the problem of controlled thermonuclear fusion (ed. Leontovich, M.A.), Vol. 3, p. 278, USSR Academy of Sciences

Wallis, M.K. (1973): Weakly shocked flows of the solar wind plasma through atmospheres of comets and planets, Planet. Space Sci., 21, 1647-1660

Wallis, M.K. and Ong, R.S.B. (1975): Strongly cooled ionizing plasma flows with application to Venus, Planet. Space Sci., 23, 713-721 




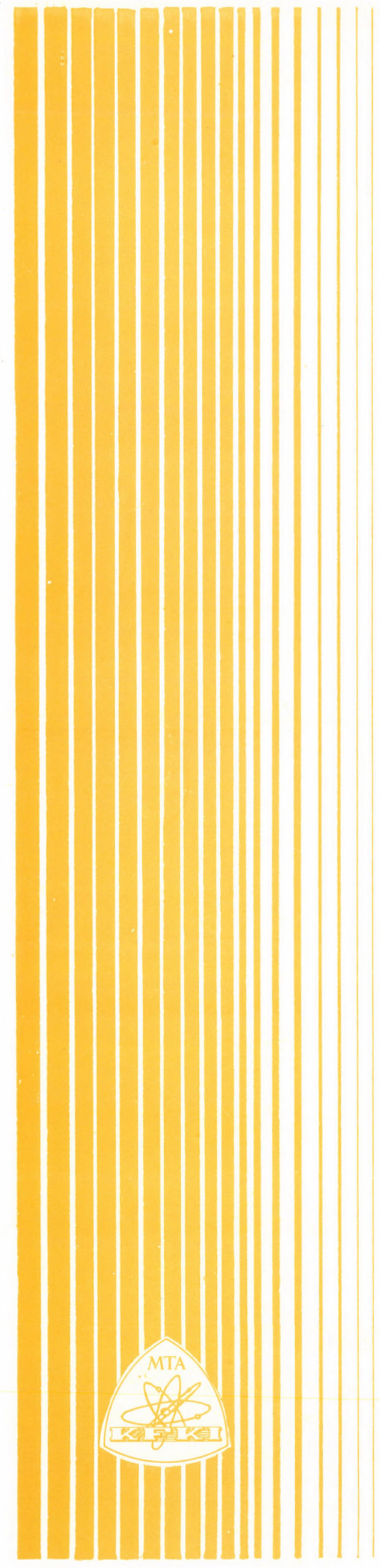

Kiadja a Központi Fizikai Kutató Intézet Felelôss kiadó: Szegố Károly

Szakmai lektor: Kóta József Nyelvi lektor: Kecskeméty Károly Gépelte: Polgár Julianna Példányszám: 380 Törzsszám: 83-163 Készült a KFKI sokszorositó üzemében Felelôs vezetô: Nagy Károly

Budapest, 1983. március hó 